\title{
Obituaries
}

\section{Griffith James Edwards CBE}

\section{Formerly Emeritus Professor, National Addiction Centre}

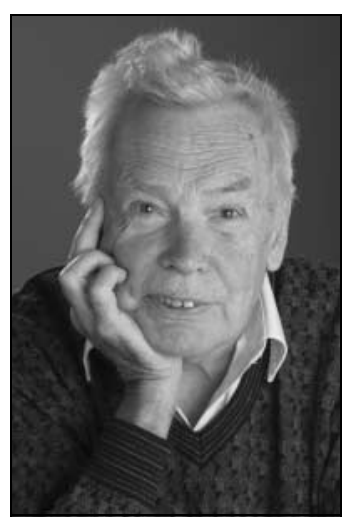

Professor Griffith Edwards, one of the world's leading experts on alcohol problems, was born in 1928 in India to an English mother and a Welsh father. He was educated at Andover Grammar School and went up to Balliol College Oxford in 1947, on a mathematics scholarship. He soon switched to medicine and his clinical studies were at St Bartholomew's Hospital, London, where he was awarded the Kirke's Scholarship and Gold Medal. From the start of his medical career he was sure that he wanted to be a psychiatrist and trained at the Maudsley Hospital in 1959, then under the dominant influence of Professor Sir Aubrey Lewis.

Griffith's interest in substance misuse in general, and in alcohol misuse in particular, was stimulated by Dr D. L. Davies, and by the mid-1960s he was leading his own research group, which by 1967 had evolved into the Addiction Research Unit, encompassing alcohol, nicotine and other drugs. The Addiction Research Unit was characterised by its multidisciplinary approach and the mix of psychiatrists, behavioural scientists and statisticians plus an anthropologist and medical historian. This was a stimulating environment from which emerged much creative research. In 1976, Griffith, with Milton Gross, published a paper with the first provisional description of alcohol dependence as a clinical syndrome. This was a landmark paper - the first time that the now familiar concept of substance dependence had been articulated. It demonstrated several facets of Griffith Edwards: his intellect, his powers of analysis and conceptual thought, and his ability to articulate complex ideas.

He was appointed to the first Chair in Addiction at the Institute of Psychiatry in 1979, and his subsequent career encompassed several interlinked strands. He continued with research, publishing more than 130 scientific papers, firmly based on clinical experience because he remained a clinician, in regular contact with patients. As problems related to alcohol and drug misuse came more and more to the forefront of public attention, Griffith's advice was frequently sought in policy formation. In the 1960s, he advised the World Health Organization on their alcohol and drug programmes and was a member of a Home Office Working Party on the Treatment of the Chronic Drunkenness Offender. Later, he became a member of the government's Advisory Council on the Misuse of Drugs, was on the Economic and Social Research Council, was advisor to the Department of Health on alcohol problems and became a member of a group advising the Cabinet Office on alcohol policy.

Another important area of his work was in editorship. This started early with the Barts students' journal but, more importantly, Griffith was Editor-in-Chief of the British Journal of Addiction from 1978 until 2005, taking it from just four issues per year to six, and then to monthly editions. He established regional offices in Australia and America, so that it is now a highly esteemed, international journal, renamed Addiction. Griffith was passionate about the journal and remained its Commissioning Editor until his death. He was also very supportive of the Royal College of Psychiatrists and chaired two committees and working groups, which led to the publication of two very informative and well-received books: Alcohol and Alcoholism ${ }^{1}$ and Drug Scenes. ${ }^{2}$

His career attracted many honours. He was the first Professor of Addiction in the UK and he was awarded: the Jellinek Prize in 1971; the Evian Health Prize in 1986; the Annual Award of AMERSA in 1990; an Honorary Professorship in the Faculty of Medicine at the University of Chile in 1992; and the Nathan B. Eddy Memorial Award in 1996. He was an Honorary Fellow of the College, and was made Commander of the British Empire (CBE) in 1987 for his services to social sciences and medicine.

The true measure of his contribution to addiction sciences is his legacy: the humble Addiction Research Unit, housed in prefabs in Denmark Hill, became the National Addiction Centre where Griffith retained an office from the time of his 'retirement' until his death, and where he retained contact with his many professional colleagues. But his legacy spreads much further than that: his students, protégés and colleagues extend worldwide. He was welcomed by friends and colleagues in most countries and they in turn were welcomed by him to his home in Greenwich. All will remember the suppers and conversations around the kitchen table. For Griffith, with his interest in everyone and everything, his superb verbal fluency, his ability to ask the penetrating question to get to the heart of an issue, stimulated everyone around him.

Griffith Edwards died on 13 September 2012 following a stroke. He leaves his wife, Sue, and children of an earlier marriage, Daniel and Rose.

1 Royal College of Psychiatrists. Alcohol and Alcoholism: The Report of a Special Committee of the Royal College of Psychiatrists. Tavistock, 1979.

2 Edwards G. Drug Scenes: A Report on Drugs and Drug Dependence by the Royal College of Psychiatrists. Gaskell, 1987.

Hamid Ghodse \& Thomas Bewley

(Professor Ghodse died on 27 December 2012, aged 74, and will be remembered in a subsequent issue of The Psychiatrist)

doi: 10.1192/pb.bp.112.042333 